\title{
CCLXXX. THE VITAMIN $B_{1}$ CONTENT OF FOODS II. ADDITIONAL VALUES
}

\author{
BY AUDREY ZILLAH BAKER \\ AND MARGARET DAVIDSON WRIGHT
}

From the Research Laboratories, Vitamins Limited, Hammersmith, London, W. 6

(Received 28 October 1938)

WE have previously published the vitamin $B_{1}$ values of about 80 foods [Baker \& Wright, 1935]. The following additional values have been obtained by the same technique. A few figures for breads, some of which have been published elsewhere [Baker et al. 1937], are included for convenience of reference. Values are given in terms of International units.

Material

Raw lean beef

Cooked tongue

Stewed steak

Stewed rabbit

Stewed tripe

Fried sweetbread

Fried bacon

Fried herring

Sweetened condensed milk

Cooked haricot beans

Cooked butter beans

Raw green runner beans

Raw cauliflower

Raw marrow

Raw fresh peas

Cooked fresh peas

Raw dried peas

Cooked dried peas

Stewed onions

Black currants

Blackberries

Melon

Fresh ripe peach

Canned peach

Syrup from peach

Raspberries

Red currants

Strawberries

Boiled rice

Ground rice

Sago

Tapioca
Dose (g.) I.U./g. Meat, offal and fish

4
6
4
6
4
6
6
4
$0 \cdot 5$
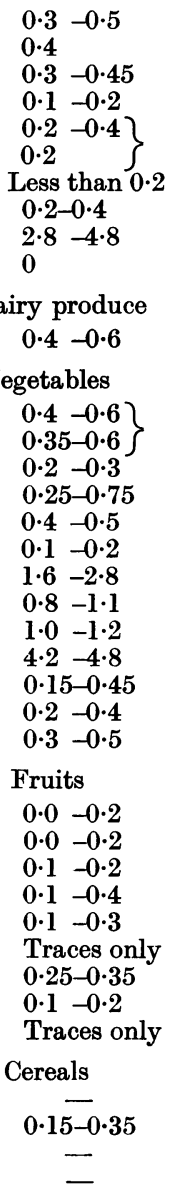

(2156)
Remarks

$0 \cdot 5$ previously published

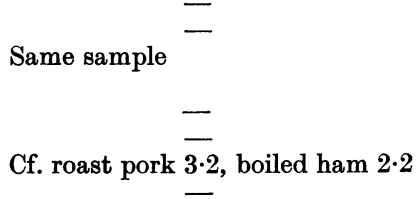

Cf. raw milk $0 \cdot 23$

Cf. raw $1 \cdot 2$

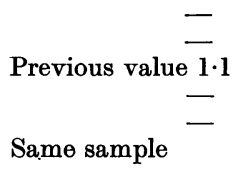

Cf. canned peas $\mathbf{1 \cdot 2}$

Cf. raw 0.4

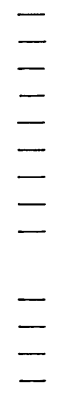




\section{Material}

Semolina (1)

Millet (Juba)

Oatmeal

Rolled oats

Black treacle W. Indian

Special brown (London): Sample (1)

Sample (2)

Special brown (Cheshire)

Wholemeal stone-ground (Cambridge)

Austrian, Sample (1) Sample (2)
Dose (g.)

Cereals (cont.)

8
4
3
2
1
2
1
2

1

3

3

3

4

3

3

$\mathbf{3}$
$0 \cdot 35-0.45$

$0 \cdot 55-0 \cdot 65$

$0 \cdot 6-1 \cdot 0$

$0 \cdot 8-1 \cdot 2$

$1 \cdot 1-1 \cdot 7$

$1 \cdot 0-1 \cdot 2$

$1.8-2.7$

$1 \cdot 45-2 \cdot 0$

Miscellaneous

Breads

$0 \cdot 45-0 \cdot 6$

$0 \cdot 6-1 \cdot 0$

$1 \cdot 2-1 \cdot 4$

$0 \cdot 4-0 \cdot 6$

$0 \cdot 35-0 \cdot 45$

$0.5-0.7$

$0.5-0.9$
Remarks

2 different samples

Previous figures $3 \cdot 25,1 \cdot 4$

Cf. previous values of other brown breads, $0.5,0.7,0.5$

Cf. previous values for wholemeal bread, $1 \cdot 1,1 \cdot 2,1 \cdot 2$

Probably in the germ bread class. Cf. previous values of other germ breads, $1 \cdot 2,1 \cdot 65,1 \cdot 7$

A bread definitely lower in vit. $B_{1}$ than others known to be wholemeal

Cf. also previously published values for white bread; 4 samples London $0 \cdot 14,0.14,0.15,2 \cdot 0$; 1 sample Scotland 0.24 ; white with malt, 2 samples, $0.35,0.35$

These foods have all been assayed by the rat-bradycardia method of Birch \& Harris [1934], and since this method has been in use in this laboratory for 4 years a few comments may be useful.

Values obtained are in good agreement with those published by other workers, e.g.:

\begin{tabular}{l}
\multicolumn{1}{c}{ Material } \\
White bread \\
Brown bread \\
Whole wheat bread \\
Wheat, whole grain \\
Bran \\
Wheat germ, raw \\
Brewer's yeast \\
Banana \\
Potato \\
Lean beef \\
Raisins
\end{tabular}

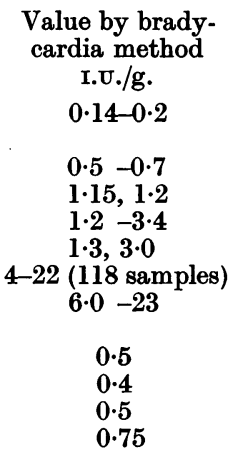

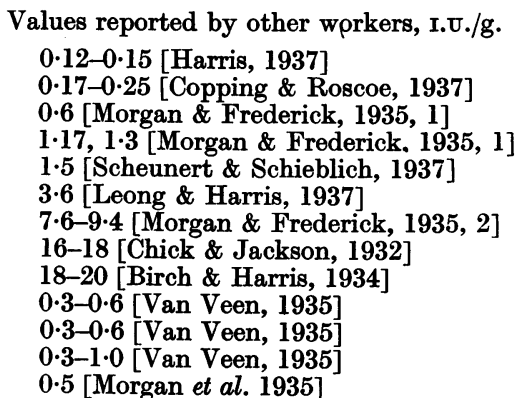

Assays repeated after long intervals have been found to give consistent results, e.g.:
White bread, sample (1) assayed 1935
(2) assayed 1936
(3) assayed 1937
$0 \cdot 0-0 \cdot 2$
$0 \cdot 1-0 \cdot 2$
$0 \cdot 1-0 \cdot 3$
Whole wheat, 1 sample, lst assay 1935
$1 \cdot 6-2 \cdot 4$
2nd assay 1936
$1 \cdot 9-2 \cdot 1$

I.U./g.

Recently Robertson \& Doyle [1937] have called attention to various difficulties in the use of the method. They find wide differences in the rats' heart rate as recorded at two portions of the same electrocardiographic tracing and also occurring after a short interval without dosage of any vitamin $B_{1}$. As the result 

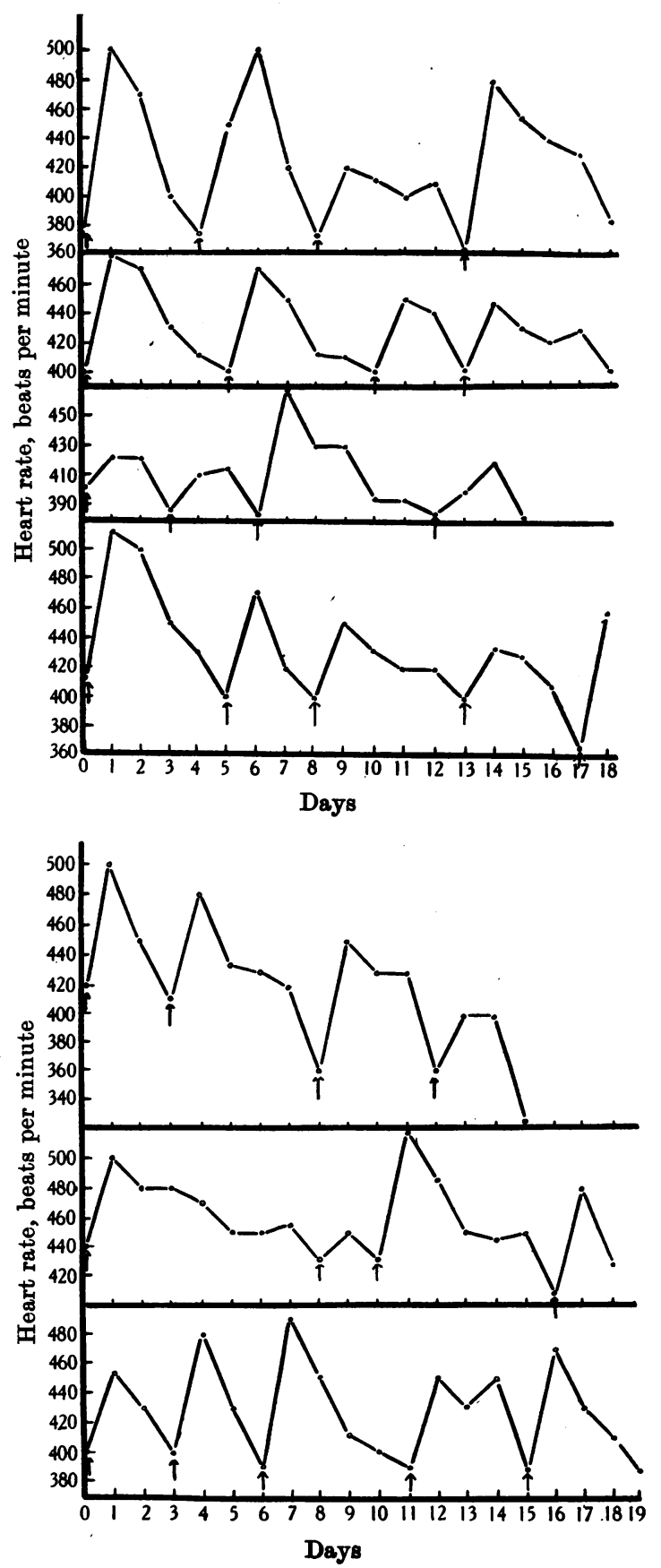

Fig. 1. [Heart rates recorded daily. Seven rats taken consecutively from the record book. 
of experience involving over 80,000 readings, we do not find these difficulties serious. Irregularities such as extra systoles and dropped beats occur sometimes, though not often, and in these cases it is important to note that it is the rhythm which is being counted, not the actual number of beats. In electrocardiographic tracings 8-10 in. long, we do not find a variation greater than 5-10 beats per min., representing $1-3 \%$ of the total heart rate and only a fraction of the variation which is brought about by an increased intake of vitamin $B_{1}$.

The accompanying graphs (Fig. 1) are records of the behaviour of a group of 7 consecutive rats taken from the daily record book. These show that the heart rate after a dose-as seen in 24-hourly readings-rises steeply and gradually drops to the initial level.

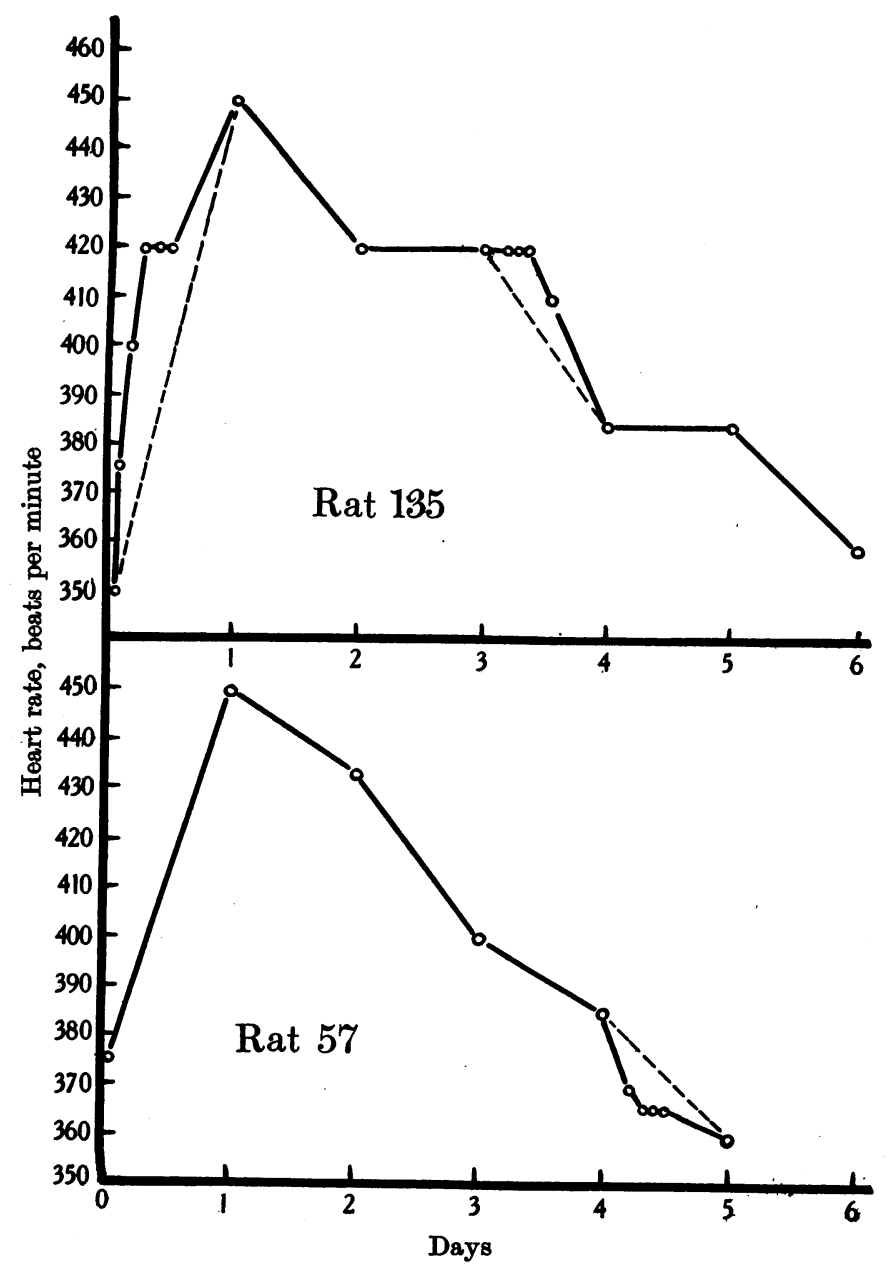

Fig. 2. Records of the heart rates of 2 rats measured 24-hourly and also at more frequent intervals to show the progressive rise or fall in heart rate. - - All readings. -- 24-hour readings.

The records of rats nos. 135 and 57 (Fig. 2) show further that readings taken at more frequent intervals fall into place with the 24-hourly ones. 
The rats' heart rate is, however, sensitive to very small variations in vitamin $B_{1}$ intake, and, while this is an advantage in permitting the assay of substances containing traces of the vitamin, it necessitates stringent care in practice to keep a continuous check on the basal diet by having 2 or 3 animals always as negative controls. That this is necessary is shown by the fact that a yeast sold commercially in America for use in vitamin $B_{1}$-deficient diets, and guaranteed to be free from vitamin $B_{1}$, was found electrocardiographically to contain about 1 I.U. vitamin $B_{1}$ per $g$. This amount in the yeast of a basal diet had actually been the cause of some puzzling results which were later explained when the presence of vitamin $B_{1}$ was known. On a basal diet completely devoid of vitamin $B_{1}$, the heart rate of a rat, if already dropping, becomes slower every day until death occurs with a rate usually of less than 300 beats per min. (see negative control graph, Fig. 3).

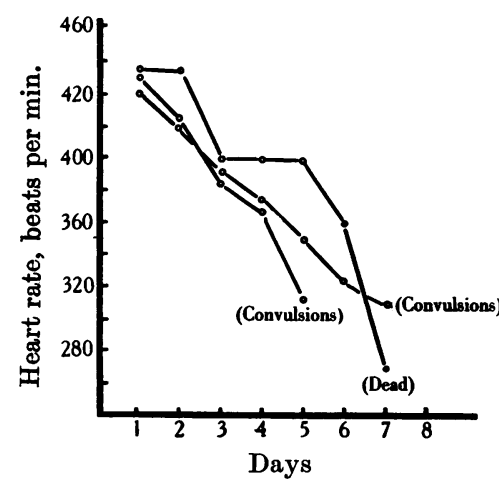

Fig. 3.

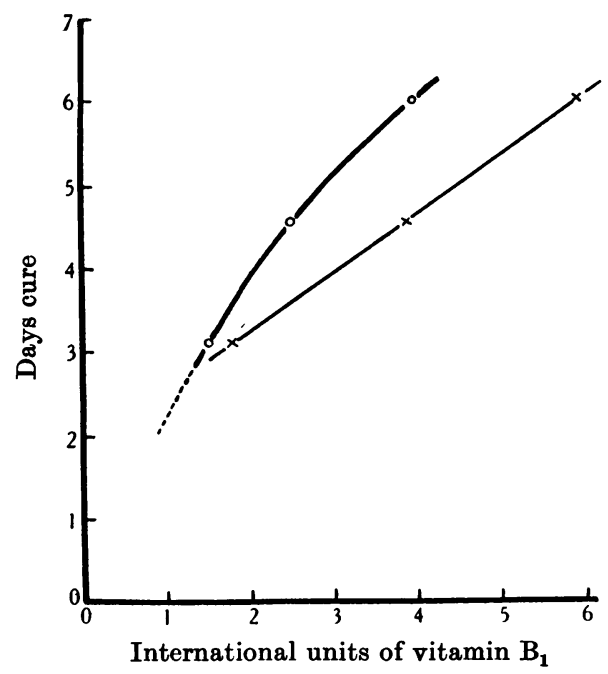

Fig. 4.

Fig. 3. Negative control records.

Fig. 4. The cardiographic response of the rat's heart to International Standard vitamin $B_{1}$. Composite curve from over 260 readings at each of 3 dose levels. 0 - Duration of cure/dose. $\times-\times$ Duration of cure/log dose.

$15 \mathrm{mg}$. Int. St. .

$3 \cdot 1$ days (283 readings)
$25 \mathrm{mg}$. Int. St. $4 \cdot 6$ days ( 280 readings)
40 mg. Int. St. $6 \cdot 0$ days (260 readings)

As in all biological assays, it is necessary to test the unknowns simultaneously with the standard of reference. In this laboratory three levels of international standard have been fed weekly and from the results obtained a considerable amount of information has been collected concerning the response to this substance. The curve shown in Fig. 4 was obtained from over 260 readings at each level and is logarithmic in form. There is little difference between the curves obtained from weekly readings and this composite curve, a fact which emphasizes the specificity of the cardiac response to vitamin $B_{1}$ and its independence of disturbing factors. 


\section{REFERENCES}

Baker \& Wright (1935). Biochem. J. 29, 1802.

- \& Drummond (1937). J. Soc. chem. Ind., Lond., 56, 191 т.

Birch \& Harris (1934). Biochem. J. 28, 602.

Chick \& Jackson (1932). Biochem. J. 26, 1223.

Copping \& Roscoe (1937). Biochem. J. 31, 1879.

Harris (1937). Biochem. J. 31, 799.

Leong \& Harris (1937). Biochem. J. 31, 812.

Morgan \& Frederick (1935, 1). Cereal Chem. 12, 390.

- $(1935,2)$. Cereal Chem. 12, 411.

Kimmel, Field \& Nichols (1935). J. Nutrit. 9, 369, 383.

Robertson \& Doyle (1937). Proc. Soc. Exp. Biol. N.Y., 37, 139.

Scheunert \& Schieblich (1937). Biochem. Z. 290, 389.

Van Veen (1935). Geneesk. Tijdschr. Ned.-Ind. 75, 2050. 